\title{
ANALISIS KELAYAKAN ISI BUKU TEKS BAHASA INDONESIA UNTUK SMAKELAS XII BERBASIS KURIKULUM 2013 TERBITAN KEMENDIKBUD
}

\author{
Firdaus Aritonang 1, Tangson R. Pangaribuan ${ }^{2}$ \\ ${ }^{1,2}$ Program Studi Pendidikan Bahasa Indonesia \\ 1,2 Universitas Negeri Medan \\ Jl. William Iskandar Psr. V Medan Estate, Medan
}

Surel: ${ }^{1}$ firdausaritonang806@gmail.com, ${ }^{2}$ tangson.rp@gmail.com

\begin{abstract}
Abstrak
Penelitian ini bertujuan untuk mengetahui (1) kelayakan isi buku teks bahasa Indonesia SMA kelas XII edisi revisi 2018 penerbit Kementrian Pendidikan dan Kebudayaan dan (2) kelayakan bahasa pada buku teks bahasa Indonesia kelas XII edisi revisi 2018 penerbit Kementrian Pendidikan dan Kebudayaan. Hasil analisis pada buku teks bahasa Indonesia SMA kelas XII edisi revisi 2018 penerbit Kementerian Pendidikan dan kebudayaan adalah sebagai berikut: (1) kelayakan isi buku teks bahasa Indonesia SMA kelas XII edisi revisi 2018 penerbit Kementrian Pendidikan dan Kebudayaan adalah 90,7\% dengan katagori sangat layak dan (2) kelayakan bahasa pada buku teks bahasa Indonesia kelas XII edisi revisi 2018 penerbit Kementrian Pendidikan dan Kebudayaan adalah 93\% dengan katagori sangat layak.
\end{abstract}

\section{Kata Kunci: Kelayakan Isi, Kelayakan Bahasa, Buku Teks}

\begin{abstract}
This study aims to find out, (1) how is the feasibility of the contents of the revised 2018 edition of the Indonesian high school textbook for the Ministry of Education and Culture and (2) what is the appropriateness of the language in the revised 2018 edition of the Indonesian textbook for the XII edition of the Ministry of Education and Culture. The results of the analysis on the revised 2018 edition of the 2018 edition of the Indonesian high school textbooks published by the Ministry of Education and Culture are as follows: (1) the feasibility of the contents of the revised 2018 edition of the Indonesian high school high school textbooks published by the Ministry of Education and Culture is $90.7 \%$ with categories very feasible and (2) the appropriateness of the language in the revised 2018 edition of the Indonesian language textbook for class XII, the publisher of the Ministry of Education and Culture, is $93 \%$ in the very appropriate category.
\end{abstract}

\section{Keywords: Feasibility of Content, Feasibility of Language, Textbooks}

\section{A. PENDAHULUAN}

Kurikulum 2013 dirancang untuk mendukung model pembelajaran abad 21. Penerapan Kurikulum 2013 menuntut siswa harus lebih aktif dalam mencari informasi dari berbagai sumber. Selain itu, dari siswa yang diberi tahu menjadi mencari tahu dari berbagai sumber belajar. Impelementasi kurikulum dalam pembelajaran sangat dipengaruhi oleh dukungan sumber belajar yang memadai. Salah salah satu sumber belajar yang memiliki peran penting 
dalam pembelajaran di sekolah adalah buku teks. Semakin baik kualiatas suatu buku teks maka akan berdampak baik pada tujuan pembelajaran.

Buku teks merupakan salah satu elemen penting dalam dunia pendidikan karena buku teks juga sebagai sumber panduan guru dan siswa. Buku teks yang bagus harus sesuai dengan ketentuan yang ditetapkan oleh Badan Standar Nasional Pendidikan (BSNP). Ketentuan yang harus dipenuhi oleh suatu buku teks adalah aspek kelayakan bahasa, penyajian, grafika, dan isi. Sedangkan hal yang harus diperhatikan dalam kelayakan isi, ada lima indikator yang harus diperhatikan yaitu (1) kesesuaian uraian materi dengan standar kompetensi (SK) atau kompetensi inti (KI) dan kompetensi dasar (KD); (2) kelengkapan materi; (3) kedalaman materi; (4) keakuratan materi; dan (5) kesesuaian materi dengan perkembangan ilmu pengetahuan, fitur, dan rujukan (Hartono 2016: 109).

Penelitian mengenai kelayakan suatu buku teks perlu dilakukan untuk mengetahui kelayakan sebuah sumber belajar. Salah satu contoh ketidaksesuaian dalam buku teks adalah yang terdapat pada buku teks Bahasa Indonesia kelas VI yang berjudul "Aku Senang Belajar Bahasa Indonesia” terbitan Graphia Buana yang disusun oleh Ade Khusnul dan M. Nur Arifin, edisi pertama, halaman 55-60 pada bulan Maret 2013. Dalam buku tersebut dalam salah satu bab yang berjudul "Anak Gembala dan Induk Serigala" yang menceritakan tentang seorang pekerja seks di warung remang- remang. Dalam cerita tersebut terdapat kata-kata yang kurang layak seperti bergairahlah lelakiku, pelukan, dan ciuman (Heryana ,2010).

Dalam penelitian Firdaus, dkk (2014) yang berjudul “Analisis Kelayakan Isi Buku Teks Bahasa Indonesia Terbitan Erlangga Kelas VII SMP/MTs". Berdasarkan hasil penelitian diperoleh bahwa buku tersebut sudah memenuhi syarat untuk kelayakan isi buku teks. Tetapi dari segi materi masih digolongkan kurang menarik. Penelitian selanjutnya adalah Pristiwana (2013) yang berjudul "Kelayakan Isi Buku Teks Pelajaran Bahasa Indonesia SMA Kelas XI" dari hasil penelitian tersebut dapat ditarik kesimpulan bahwa buku teks mempunyai presentasi kelayakan sebesar $75 \%$.

\section{B. KAJIAN TEORI}

Buku teks merupakan buku yang dipakai untuk menjadi panduan dalam belajar yang digunakan oleh guru dalam pembelajaran di kelas. Sedangkan bagi siswa untuk mempermudah dalam mengikuti proses pembelajaran dalam buku teks tersebut. Buku teks diharapkan sesuai dengan rangkaian yang bertahap atau sistematis agar pengguna baik guru maupun peserta didik yang memakai buku tesebut paham apa yang diuraikan dalam buku tersebut.

Buku teks yang digunakan dalam pembelajaran harus memiliki kualitas sesuai dengan 
ketentuan yang sudah ditetapkan oleh BNSP yang harus dicapai dalam buku yang akan diterbitkan. Yang harus diperhatikan, yaitu;

1. Harus memuat isi yang sesuai materi pelajaran

2. Dalam buku harus memuat bahasa dan keterbacaan sesuai ketentuan BNSP

3. Penyajian materi

4. Dan Format buku yang sesuai ketentuan

BNSP dalam (Muslich 2010: 292) berpendapat terdapat faktor-faktor yang dapat menjadi penilaian dalam suatu buku teks pelajaran yang didalamnya harus meliputi penilaian kelayakakan isi, kelayakan bahasa, kelayakan penyajian, dan kelayakan grafik..

1. Kelayakan Isi Buku, terdapat indikator pencapaian dalam kelayakan isi buku yang harus diperhatikan yang memuat bagaimana kesesuaian antara materi dan KI/KD dalam buku yang sesuai dengan tuntutan kurikulum kemudian didalam buku tersebut harus juga memuat keakuratan materi yang terdapat dalam buku yang harus memperhatikan contoh yang dimuat dan soal-soal yang terdapat dalam buku dan terakhri materi pendukung pembelajaran yang dimuat yang terbaru yang sesuai ketentuan yang sudah diterapkan.

2. Kelayakan penyajian dalam buku, beberapa yang harus diperhatikan dalam penyajian dalam buku yaitu bagaimana teknik penyajian yang dimuat yang sesua indikator yang tersistematika, kemudian penyajian pembelajara yang akan digunakan dalam pembelajaran yang mengacu pada kurikulum, dan kelengkapan penyajian yang harus memperhatikan setaip aspek yang ada dalam buku baik berupa gambar, ilustrasi atau simbol yang terdapat dalam buku.

3. Kelayakan bahasa yang harus dan harus diperhatikan yang sesuai indikator dalam buku teks yaitu kesesuaian perkembangan bahasa pada tingkatan siswa yang harus diperhatikan dalam pembuatan buku teks agar sesuai dengan taraf pemikiran perkembangan pada tingkatan peserta didik, pemakaian bahasa sesuai dengan kognitif yang artinya melibatka hubungan dengan kognisi menilai dan mampu mempertimbangkan suatu peristiwa, dan pemakaianbahasa keterpaduan alur dan keruntutan yang artinya harus sesuai dengan sipemakai bahasa tersebut sesuai tingkatan dan memperhatikan urutan yang logis dalam setiap bab dalam buku teks.

4. Kelayakan grafik, terdapat penilaian indikator yang dimuat dalam kegrafikan dalam setiap penerbitan buku teks yang sesuai kegrafikan yang sudah ditentukan oleh Bnsp yaitu; ukuran buku yang sesuai standar buku nasioanal yang sesuai kemudaian desain kulit buku teks yang dimana harus diperhatiakan antara desain kulit depan buku dengan 
belakakang yang seirama, dan layout isi buku yang menarik agar pembaca merasa mendapat kesan bahwa buku tersebut baik harus. (Muslich 2010: 305)

\section{METODE PENELITIAN}

Penelitian ini menggunakan metode penelitian kualitatif. Penelitian ini menghimpun, mengindetifikasi, menganalisis, dan mengadakan pencarian data-data yang terdapat pada sumber data yaitu buku bahasa Indonesia kelas XII tahun 2018. Indikator untuk melihat kelayakan buku teks adalah sesuai ketentuan Badan Nasional Standar Pendidikan (BNSP) ditinjau dari segi kesesuaian Kompetensi Inti dan Kompetensi dasar, keakuratan materi, dan kelayakan pada bahasa.

\section{HASIL PENELITIAN DAN PEMBAHASAN}

Berdasarkan Indikator BSNP (Badan Standar Nasional Pendidikan) yang telah ditentukan dalam analisis pada buku ini yaitu buku bahasa Indonesia SMA Kelas XII, dan telah didapatkan hasli penelitian sebagai berikut.

Tabel 1 Hasil Kelayakan Isi Buku

\begin{tabular}{ccc}
\hline Bab & Skor & $\begin{array}{l}\text { Presentase } \\
(\%)\end{array}$ \\
1 & 41 & 93 \\
2 & 37 & 84 \\
3 & 38 & 86,3 \\
4 & 43 & 97,7 \\
5 & 43 & 97,7 \\
6 & 38 & 86 \\
& Jumlah Rata-rata & 90,7 \\
\hline
\end{tabular}

Tabel 2 Hasil Kalayakan Bahasa

\begin{tabular}{ccc}
\hline Bab & Skor & $\begin{array}{l}\text { Presentase } \\
(\%)\end{array}$ \\
1 & 22 & 91,6 \\
2 & 23 & 95,8 \\
3 & 24 & 100 \\
4 & 23 & 95,8 \\
5 & 21 & 87,5 \\
6 & 21 & 87,5 \\
Jumlah Rata-rata & 93 \\
\hline
\end{tabular}

Dari tabel di atas terlihat bahwa kelayakan isi mencapai persentasi 90,7\% dan kelayakan bahasa $93 \%$. 


\section{Kelayakan pada isi Buku Teks Bahasa Indonesia SMA Kelas XII Edisi Revisi 2018 Terbitan Kemendikbud.}

Jumlah keseluruhan pada penilaian kelayakan is i pada buku teks pelajaran SMA Kelas XII adalah 90,7\% dengan katagori sangat layak. Adapun rincian indikator untuk kelayakan pada isi akan disajikan sebagai berikut.

a. Kelengkapan Materi

Dalam buku bahasa Indonesia kelas XII untuk kelengkapan materi mendapat skor 83,3\% dengan tingkatan sangat layak, hal tersebut dinilai dari beberapa bab yang sudah lengkap dan didalamnya membahas kompetensi inti dan kompetensi dasar yang sudah memuat sesuai dengan tujuan pembelajaran seperti disajikan pada setiap wacana, soal latihan, dan contoh seperti di bab 2 dan 4 dengan katagori sangat layak. Dan ada beberapa bab yang tidak menyajikan dan kurang dalam menyampaikan kompetensi inti pada buku tersebut seperti di dalam bab 1, 3, 5, 6 tidak memuat KI sama sekali. Seperti yang telah disampaikan oleh Muslich (dalam Jurnal Kata 2014: 3) setiap materi yang ada dalam buku pelajaran harus memuat KI dan KD di dalam materi yang ditampilkan untuk mendukung tercapainya kurikulum yang dirumuskan.

b. Kedalaman Materi

Untuk kedalaman materi pada buku teks SMA kelas XII ini mendapat skor $100 \%$ atau katagori sempurna. Hal tersebut karena sudah didukung definisi, konsep yang ada di dalam buku, prinsip, prosuder, dan latihan yang telah ditetapkan sesuai kompetensi inti dengan kompetensi dasar yang sudah di paparkan pada semua rincian bab yang dimuat dalam buku dari bab 1-6 dalam buku tersebut dan sudah tersaji dan disesuaikan dengan perkembangan kognitif siswa.

c. Pemilihan Wacana, Teks, Gambar, dan Ilustrasi Sesuai dengan Kompetensi yangHarus Dicapai dan Bermanfaat Bagi Pemenuhan Rasa Ingin Tahu Peserta Didik.

Untuk poin ketiga dalam hal ini sudah memenuhi kriteria yang ditentukan dan sudah menyebutkan semua sumber dengan jelas sesuai pedoman BNSP dan sanggat sesuai dengan tingkat pemahaman peserta didik dan pemenuhan bagi rasa ingin tahu pesera didik sehingga mendapat skror $100 \%$ baik dari menyajikan wacana, teks, ilustrasi dan latihan yang bermanfaat untuk pemenuhan rasa ingin tahu peserta didik. 
d. Konsep dan Teori Sesuai dengan Definisi yang Berlaku dalam Bidang Ilmu

Kesesuaian konsep dan teori sesuai dengan definisi yang berlaku dalam bidang ilmu sudah sesuai karena sudah memenuhi podoman BNSP sehingga mendapatkan skror 100\%. Hasil tersebut diperoleh dari bab 1-6 yang telah menyajikan semua aspek yang ada dalam buku bahasa Indonesia kelas XII dan sudah memenuhi sesuai dengan definisi yang berlaku dan tidak ada yang menimbulkan makna ganda atau membingungkan bagi siswa, serta teori yang dikemukakan juga sesuai dengan bidang ilmu.

e. Pemilihan Contoh Sesuai dengan Kompetensi yang Harus Dicapai

Pemilihan contoh sesuai dengan kompetensi yang harus dicapai memperoleh skor 100\% dari keseluruhan bab yang ada dalam buku tersebut. Keseluruhan bab sudah menyajikan secara akurat sesuai dengan kompetensi yang akan dicapai. Keseluruhan bab tersebut menanamkan semua aspek yang ditentukan seperti didalamnya ada contoh yang sesuai, fakta, dan ilustrasi yang ada pada buku teks yang tidak menimbulkan makna ganda dan tidak membinggungkan bagi siswa.

f. Pelatihan, Penugasan, dan Penilaian Sesuai Tuntutan Penilaian Autentik

Untuk pelatihan, penugasan, dan penilaian memperoleh nilai $100 \%$. Hal tersebut dinilai dari beberapa aspek penilaian berupa soal-soal, tugas, dan forum diskusi yang sudah sesaui dengan tuntutan penilaian autentik.

g. Kesesuaian dengan Perkembangan Ilmu

Dalam buku bahasa Indonesia kelas XII edisi revisi 2018 untuk aspek kesesuaian dengan Perkembangan Ilmu memperoleh skor dengan nilai 91,6\% atau memperoleh katagori sangat akurat. Dari 6 bab hanya 1 bab yang memperoleh skor akurat di karenakan terdapat materi yang kuranng menyajikan kesesuaian yang telah ditentukan dengan tingkat pemahaman peserta didik.

h. Kesesuaian Fitur/Contoh/Latuhan/Rujukan

Kesesuain dalam hal ini dalam buku pelajaran bahasa Indonesia kelasXII tahun tebit 2018 ini memperoleh skor 95\% dengan katagori sangat layak. Hal tersebut dikarenakan dari 6 bab pada buku tersebut hanya 1 bab yang terdapat dalam buku tersebut menggunakan rujukan yang kurang relevan pada kondisi saat ini. Seperti yang telah disampaikan oleh Muslich (dalam Jurnal Kata 2014: 4) tentang hal ini ada kententuan yang mengenai rujukan dimana 
rujukan tersebut yang layak yang sesuai dengan perkembangan yaitu lima tahun terakhir.

i. Pengembangan Wawasan Kebhinekaan

Dalam buku bahasa Indonesia kelas XII edisi 2018 ini terdapat beberapa bab yang belum menyajikan mengenai poin ini baik dalam pembahasan materi, pelatihan, contoh, dan wacana memperoleh nilai 70,1\% dengan katagori kurang. Pengembangan wawasan kebhinekaan kurang disajikan baik dari wacana, materi, dan latihan dari keseluruhan bab. Ada satu bab yang memuat kriteria dari BNSP dari setiap aspek yang dinilai baik dari menampilkan keberagaman dan ilustrasi yang dapat membuka wawasan kepada pserta didik mengenai mencintai dan menghargai keberagaman yang ada.

j. Pengembangan Wawasan Kebangsaan dan Integrasi Bangsa

Pada pengembangan wawasan kebangsaan dan integrasi bangsa diperoleh nilai $70,8 \%$ baik dalam materi, pelatihan, dan contoh. Dari keseluruhan bab dalam buku tersebut, hanya satu bab yang lengkap dengan menyajikan indikator untuk mengenal budaya dan pengenalan leluhur budaya. Melalui pengenalan tersebut diharapkan dapat meningkatkan nasionalisme peserta didik.

k. Tidak Mengandung Unsur Sara, Haki, Pornografi, dan Bias.

Dalam buku bahasa Indonesia kelas XII ini mendapatkan poin sempurna 100\%, hal tersebut karena semua bab tidak ditemukan unsur sara, Haki, pornografi dan bias. Karena baik contoh, penugasan, dan setiap ilustrasi tidak ditemukan unsur tersebut.

\section{Kelayakan Bahasa pada Buku Teks Bahasa Indonesia SMA Kelas XII}

\section{Terbitan Kemendikbud}

Jumlah Presentase nilai yang didapat dari setiap aspek kelayakan bahasa pada buku bahasa Indonesia kelas XIITerbitan Kemendikbud dengan skor 93\%,berikut rincian setiap aspek yang diamati.

a. Kesesuaian dengan Tingkat Perkembangan Intelektual Peserta Didik

Untuk kesesuain dengan tingkat perkembangan intelektual peserta didik mendapat nilai 91,6 dengan katagori sangat sesuai. Hal tersebut disajikan pada buku ini dalam bentuk wacana, gambar, teks dan latihan yang secara imajinatif sesuai dengan tingkat perkembangan intelektual peserta didik. 
b. Kesesuaian dengan Tingkat Perkembangan Sosial Emosional Peserta Didik

Untuk kesesuaian bahasa yang terdapat dalam buku bahasa Indonesia kelas XII ini memperoleh skor dengan jumlah 95,8 dengan katagori sangat layak. Hal tersebut karena bahasa dalam buku tersebut sesuai dengan tingkat perkembangan sosial emosional peserta didik.

c. Keterbacaan Pesan

Pada poin keterbacaan pesan memperoleh skor $87 \%$ dengan katagori baik. Semua bab dalam buku tersebut menyampaikan keterbacaan pesan dalam bahasa yang menarik, jelas, dan tepat sasaran. Namum pada beberapa kalimat dalam buku bahasa Indonesia ini ditemukan kalimat yang ambigu.

d. Ketepatan Bahasa

Dalam buku bahasa Indonesia kelas XII ketepatan bahasa mendapat rentang $87 \%$,hal tersebut diamati dari penggunaan bahasa yang digunakan dalam buku tersebut untuk menyampaikan pesan mengacu pada kesesuaian yang telah sesuai dengan kaidah bahasa Indonesia. Tetapi beberapa bab yang disajikan dalam buku ini, penggunaan istilah yang menggambarkan suatu konsep, prinsip, atau sejenisnya kurang tepat berdasarkan PUEBI. Hal tersebut terlihat pada bab 4, 5 dan 6.

e. Keruntutan dan Keterpaduan Bab

Untuk keruntututaan antara setiap materi yang diamati sesuai dengan urutan dan berkesinambungan dalam hal ini mendapatkan $100 \%$ dengan katagori sempurna. Buku ini sudah sangat baik dan logis karena setiap yang bab ke bab yang lain telah menunjukan keruntutuan dan keterpaduan bab dan memiliki hubungan yang logis.

f. Keruntutan dan keterpaduan Paragraf

Dalam poin keruntutuan dan keterpaduan paragraf, buku bahasa Indonesia kelas XII tahun 2018 memperoleh 100\%. Hal ini karena semua teks memiliki keruntutuan dan keterpaduan paragraf sehingga tidak membingungkan peserta didik. 


\section{E. KESIMPULAN}

Berdasarkan hasil penelitian, bahwa buku bahasa Indonesia SMA Kelas XII edisi revisi 2018, terbitan Kemendikbud dari segi kelayakan isi pada katagori sangat layak dengan memperoleh skor $90,7 \%$ dan dari segi kelayakan bahasa memperoleh skor $93 \%$ dengan katagori sangat layak. Berdasarkan hasil tersebut maka buku bahasa Indonesia kelas XII SMA sangat layak dan sudah sesuai dengan kriteria yang telah ditentukan BNSP.

\section{F. SARAN}

Berdasarkan hasil yang telah ditemukan dalam buku bahasa Indonesia SMA kelas XII terbitan Kemendikbud sudah memenuhi kriteria sesuai Badan Standar Nasional Pendidikan (BNSP). Untuk selanjutnya, diharapkan pada penyusunan berikutnya untuk menambah wawasan tentang budaya atau keragaman budaya Indonesia dalam materi buku teks. Harapannya dengan penambahahan materi tentang budaya Indonesia maka akan menambah pengenalan dan kecintanan terhadapa budaya Indonesia bagi peserta didik.

\section{DAFTAR PUSTAKA}

Departemen Pendidikan Nasional. 2005. Peraturan Menteri Pendidikan Nasional Nomor 11 Tahun 2005 tentang Buku Teks Pelajaran. Jakarta: Departemen Pendidikan Nasional

Depdiknas. 2008. Kamus Besar Bahasa Indonesia. Jakarta: Balai Pustka Firdaus, Aziz, Siti Samhati dan Edi Suyanto. 2014. Analisis Kelayakan Isi Buku Teks Bahasa Indonesia Terbitan Erlangga Kelas VIII SMP/MTs. Jurnal Kata. FKIP Universitas Lampung

Hendrawanto, Y. 2017. Kelayakan Buku Teks Bahasa Indonesia SMA/SMK: Analisis Kebahasaan, Isi, Penyajian, Kegrafikaan, dan Keterbacaan. Semarang: Pascasarjana Universitas Negeri Semarang

Heryana, Dadan dan Giri Verianti. 2010. Pendidikan Jasmani, Olahraga, dan Kesehatan. Jakarta: Pusat Pusat Perbukuan Kementerian Pendidikan Nasioanl.

Indriani Nisja. 2016. Kesesuaian Buku Teks Bahasa dan Satra Indonesia Kelas X dengan Kurikulum 2013. Jurnal Gramatika. STKIP PGRI Sumatera Barat

Kartikasari, Yulia. dkk. 2015. "Kelayakan Isi dan Bahasa Ada Buku Teks Bupena Bahasa Indonesia Kelas VII'. Jurnal Kata. Hal. 1-6

Pradita, Ridho M., \& Fitriani Lubis. 2018. Kelayakan Isi dan Bahasa Buku Ajar Bahasa Indonesia Sekolah Menengah Pertama Kelas VIII Kurikulum 2013 Edisi Revisi 2017 Penerbit Kementerian Pendidikan dan Kebudayaan. Basastra: Jurnal Kajian Bahasa dan Sastra Indonesia, Vol 7, No 4, hal 281- 294 
Peraturan Pemerintah No. 32 Tahun 2013 tentang Standar Nasional Pendidikan. Jakarta: Depdiknas

Rineka Cipta Badan Standar Nasional Indonesia. Instrumen Penilaian BukuAjar.(http://bsnp-indonesia.org/2014/05/28/instrumen-penilaian-buku-tekspelajarantahun-2014/) diakses 20 Oktober 2020

Pristiwana, Winanda. 2013. Kelayakan Isi Buku Teks Pelajaran Bahasa Indonesia SMP Kelas VII. Skripsi. FBS Universitas Negeri Medan

Tarigan, Henry Guntur dan Djago Tarigan. 2009. Telaah Buku Teks Bahasa Indonesia.Bandung: Angkasa

Sitepu, B.P. 2012. Penulisan Buku Teks Pelajaran. Bandung: Remaja Rosdakarya. Badan Standanr 